\title{
THE ROCKET-BAROQUE PHASE OF THE ICECREAM VERNACULAR: ON REYNER BANHAM'S CRITICISM OF ARCHITECTURE AND OTHER THINGS
}

\author{
NAOMI STEAD \\ Faculty of Design, Architecture and Building \\ University of Technology, Sydney \\ PO Box 123, Broadway, NSW 2007, Australia
}

Naomi.stead@uts.edu.au

\begin{abstract}
Throughout his trans-Atlantic career as a critic and commentator, Reyner Banham turned his attention to a vast range of objects, places and activities. This is especially true of his writing in the 1970's and 80's, after he was invited by New Society to write (according to Mary Banham) on 'almost any subject that intriuged him'. Mary Banham notes that 'From boyhood Reyner Banham's interests had been very wide indeed, his curiosity particularly aroused by the unexpected and the incongruous and most particularly by anything with wheels and/or an engine,' and his writing is indeed marked by a respect, concern, and fascination for technical matters, in architecture and elsewhere. But the essays from this period, ranging as they do from 'reviews' of the potato crisp to the bolo tie, the clipboard to the first Star Wars movie, also serve to raise a series of questions about architectural criticism. Banham turned his specifically architectural sensibility to a startling array of non-architectural, technological and practical things, but what criteria did he use to evaluate these? How did these criteria differ from those he used in his more conventional architectural criticism in the same period? And perhaps most importantly, how was Banham able to reconcile practical, technological, formalist, programmatic and historical issues, whether in a building or a Gulfstream caravan, in his arrival at aesthetic judgement? This paper will examine selected essays from Banham's critical oeuvre to open the question of how his criteria for judgement shifted according to the nature of the object he was examining, and what this might mean more broadly for the theory and practice of architectural criticism in relation to technology.
\end{abstract}

\section{Introduction}

In his address to the 1964 conference of the American Institute of Architects and American Collegiate Schools of Architecture teacher seminar, Reyner Banham quipped that 'history is... my academic discipline. Criticism is what I do for money' (Banham 1965: 91). Now while this may have been a throw-away line, played for laughs, it provides a fitting introduction to this paper, since the distinction between the scholarly, rigorous, academic practice of history and the essayistic, journalistic, opinionated and rhetorical practice of criticism lies at the centre of my concerns here. The distinction, or polarisation, between a highly theorised and arcane critical 
discourse published as long essays in academic journals, and short accessible journalistic articles in glossy commercial magazines, has dominated architectural theory for the past thirty years. It can be held at least partly responsible for what is widely seen as a present malaise in the culture and practice of architectural criticism. As Susanne Stephens notes, 'the absence of well-thought-out standards for evaluation, a weak cultural context for debate, and the critic's need to write for several audiences with different needs and levels of knowledge are significant barriers' (Stephens 1998: 68). The present paper represents new work in a larger project that seeks to understand the widespread contemporary belief in a state of crisis in architectural criticism. The larger question here, then, is what Banham's work could continue to offer, nearly twenty years after his death, to architectural criticism in the present day.

If we accept judgement and evaluation, alongside interpretation, as key aspects of the value and purpose of architectural criticism, then how does an architectural critic derive and determine their criteria for judgement? How, especially, does a critic like Banham do this given the extraordinarily broad range of items that he evaluates - whether 'conventional 'high art' architecture, the styling of household appliances, or the latest science fiction puppet series on television' (Whiteley 1990: 188). In this context Banham provides a useful test case - as one of the most prolific and vociferous critics of the twentieth century, he opens both the question and the process of architectural criticism precisely by including it as one part of a much broader critical practice, on a continuum with popular culture criticism and what would later come to be called design criticism. His oeuvre thus allows us to pick out the commonalities, and distinctions, between various modes of critical work. Two interrelated themes immediately emerge: the significance Banham places on the social aspects of function and human use, and the common thread formed by his thoroughgoing interest in technology. As Romy Golan has noted, 'Banham is one of the best reads, ever, on architecture. Yet at the same time few have shared his fixation with technology' (Golan 2003: 401). Banham himself noted, in the foreword to the first anthology of his critical writing published in 1981 as Design by Choice, that 'if the tone and style change, [from one publication to another] it should be clear that one thing does not - my consuming interest, through thick and thin, hardback and limp, in what happens along the shifting frontier between technology and art' (Banham 1981: 7).

\section{Banham the engineer}

In this context, much has been made of Banham's background and education in engineering he undertook an apprenticeship in the engine division of the Bristol Aeroplane Company during the second world war (Whiteley 1990: 188). In much of the commentary on his writing the implication has accordingly been that he was not only theoretically concerned with, but actually understood, the way that mechanical and technological things work. Peter Hall writes that Banham 'started from his absolute engineer's knowledge of what things were like and how they really worked which made him impatient with - and contemptuous of - any theory that did not spring from the deep soil of experience' (Hall 1996: xiii). Romy Golan speculates that Banham 'probably would have liked to be described as the smartest engineer to have written about architecture' (Golan 2003: 401), while Mary McAuliffe writes that

One of his most enduring themes, influenced by an engineering apprenticeship... was the emancipation, abundance, and pleasure offered by twentieth-century technology... Banham urged architects to discard their artistic pretensions and run with the "fast company" of scientific and engineering experts (McAuliffe 2000: 269).

Banham's engineering training was later balanced by an opposite extreme, when he studied for a PhD under the supervision of Nikolaus Pevsner at the Courthauld Institute of Art in London, whilst concurrently working as a journalist for the Architectural Review. His doctoral thesis was published in 1960 as Theory and Design in the First Machine Age, and it became the book that made his reputation. In this text he was concerned with the historiography as much as with the actual history of the Modern Movement, attempting to unearth and re-evaluate the legacy of early modernists such as Bruno Taut and Filippo Marinetti, and in the process questioning the monolithic and self-enclosed version of Modern architectural history that had been written by 'the triumvirate of grandstyle architectural historians' represented by Pevsner, Siegfried Giedion, and Henry-Russell Hitchcock (Golan 2003: 401).

It would be too easy to say that architecture provided the middle ground that allowed Banham to bring together his interests in technology and art, but nevertheless there is something in the complex functionality of architecture that surely provided a foil for Banham's concern with both use and symbolic expression. He chose as his critical subjects a truly wild profusion of things, 
places and products, but as Walter Vanstiphout notes, his work has several key common threads.

From the admiration for car designers of Detroit, to the analysis of ice-cream-cart art, the evocation of power stations, the execration of the Getty Museum, the historiography of the motel, the archaeology of the sheriff's star, the anthropology of the bolo tie, the survey of Frank Lloyd Wright, all the way to the celebration of air shows, Banham's critique of design was always founded in a strong commitment to the people who were using and adapting and living on the land (Vanstiphout 1998: 2).

Banham was an amazingly prolific critic. Aside from his twelve published books, Whiteley counts over 750 magazine articles or reviews Banham published between 1950 and his death in 1988 (Whiteley 2002: 328). Banham is most closely associated with the weekly journal New Society, to which he was a regular contributor for twenty-four years, producing a colossal 235 essays in a column entitled 'Society and Design'. But between 1958-1965 he also wrote regularly for the left-wing journal New Statesman, and between 1956-1964 contributed the 'Not Quite Architecture' column to Architects' Journal. Less well known is his work for a host of other art, design, and architecture journals, and his early regular contribution to Art News and Review, for which he reviewed art exhibitions, before turning to the architectural and technological subjects with which he is most associated.

\section{The Banham Legacy}

In recent years the examination of Banham's legacy has continued apace. This has been assisted by the two anthologies of his criticism, Penny Sparke's 1981 collection Design By Choice and A Critic Writes, released after Banham's death, in 1996. In addition, any recent work on Banham (including this paper) is indebted to Nigel Whiteley's authoritative Reyner Banham: Historian of the Immediate Future, published in 2002. Reviews of that book have noted the political aspect of Banham's practice, and the way that towards the end of his career he came to be 'outflanked' by both sides of the political spectrum, 'on the right, by traditionalists who found his preoccupation with Barbarella and corporate logos unseemly, and on the left, by a more socially conscious generation for whom his delight in the "aesthetics of expendability" seemed an extended apologia for mindless consumerism and a culture of waste, superficiality, and environmental irresponsibility' (Katz 2002: 799).

In the context of this small body of key literature, it is worthwhile to briefly examine the way these different works curate and order the Banham oeuvre. The Design by Choice anthology is divided into two sections, the first devoted to 'Twentieth-Century Architecture - History, Theory and Criticism' and the second to 'Pop Culture - Theory and Design'. This may seem a rather rigid categorisation going against Banham's own synthetic and inclusive practice, which looked to break down hierarchical barriers between 'high' and 'pop' culture. But this division is nevertheless interesting for the contrast it sets up, between strictly and conventionally 'architectural' criticism, for instance the canonical essay on Stirling and Gowan's Faculty of Engineering Building at Leicester University entitled 'The Style for the Job', and the essays which attempt to assimilate and understand popular culture, such as 1955's 'A Throw-Away Aesthetic', in which was derived a conceptual armature and methodology for much of Banham's later design criticism.

The later anthology A Critic Writes has a much lighter curatorial touch on the part of the editors, with very little critical commentary or contextual information, and the essays arranged chronologically. This means that the full breadth of Banham's interests are allowed to sit in happy juxtaposition rather than in thematic clusters. In turn, the title of Whiteley's book plays cleverly on the intertwined temporality of history and criticism in Banham's oeuvre. If history is a critical approach to the past, then criticism is a historically-informed approach to the present which will, in turn, contribute to the writing of buildings and projects into the historical record. One might very well say then that any critic is a historian of the immediate future, but the thing that makes this such an appropriate description of Banham's work is his attention to pop culture, to the passing parade of 'noisy ephemeridae' (as he put it in an early essay on car design entitled 'Vehicles of Desire') that makes up the everyday commercial vernacular. In some ways his writing itself was a contribution in the spirit of this transience, and Banham was clearly well aware of this when he wrote that

The splendour (and misery) of writing for dailies, weeklies, or even monthlies, is that one can address current problems currently, and leave posterity to wait for the hardbacks and $\mathrm{PhD}$ dissertations to appear later... the splendour comes, if at all, years and years later, when some flip, throw-away, smarty-pants look-at-me paragraph will 
prove to distil the essence of an epoch far better than subsequent scholarly studies ever can (Banham 1981: 7).

This temporality of the various modes of Banham's writing has also been commented upon by Penny Sparke, who writes that '[m]any of his articles are 'essays' for his books - particularly his architectural pieces - but the others, on a cross-section of mass culture, serve to translate the ephemeral values within this area of culture into an equivalent language which adequately describes them.' The magazine essays thus have some of the transience and apparent expendability of the things they discuss. Magazines themselves are consumed and then abandoned in the same economy as many of the other items of pop culture that Banham celebrates, unlike books - and architecture - which are designed and intended for longevity. The essays also employ a very distinctive mode of writing, an exuberant, impudent and rollicking polemical style, which swings along at helter-skelter pace. In this Golan notes the influence of Fillipo Marinetti, who 'gave Banham the prose stylist an irrestistable model for an exhilarated and iconoclastic way of writing', as well as the broader disposition of both Futurism and Dada, in 'the way both aimed to touch every aspect of life' (Golan 2003: 402). The space limitations inherent to writing for magazines mean that many ideas are touched upon without being fully developed, but this too is part of the pleasure of this mode of writing - it is a hors d'oeuvre rather than a main course.

\section{Design criticism}

Much of Banham's written oeuvre has come to be understood as design criticism, and indeed a large part of his significance as an historical figure derives from his contributions to the then nascent discourse of design studies. But this too opens a significant question in the present context - what is the distinction between design criticism and architectural criticism? Does this imply that the criteria which architectural criticism might bring to bear in judgement of an object are different from those of design criticism? And what might these respectively be?

In order to approach this question, it is worthwhile to look a little more closely at some of Banham's writing, and to do so through Whiteley's brilliant analysis of Banham as a design critic. He explains that for Banham, the function of a thing and its signification or symbolic expression are not divided but inextricably linked through human use, which is to say the way it is consumed within a specific social context. This is distinct from a more objectival concept of use, a 'quasi-ergonomic' one 'by which modernist designers tended to mean the graspability of a handle or pourability of a spout, for example' in that use itself becomes something culturally meaningful. Whiteley gives as a case study the article 'Shades of Summer', published in New Society in 1967 (Whiteley 1997: 26). In this essay Banham analyses a particular brand of sunglasses pitched at the surfer-girl market and known as 'Boywatchers'. He finds that their functions fall into three categories, the 'prime function' being 'to keep the hair tidy, the secondary function... to conceal eye movement while studying form (hence the name) and, in extreme circumstances only, to shield the eyes from glare' (Banham 1967: 959). Such an approach, aside from its amusing and lateral analysis of a consumer item in terms of the actions, identity, and subculture of a particular slice of society, makes no distinction at all between the form of the sunglasses and their signifying function. In fact the signifying function, the meaning of the object, is only ever revealed through its social use, not through a formalist analysis of the thing in itself. Further, Whiteley argues that Banham's mode of critique recognised the crucial role that design plays in a postmodern society, in the fashion-conscious construction of identity.

\section{Functional considerations}

In attempting to understand the commonalities and distinctions between Banham's design and architectural criticism through the vehicle of technology, and particularly its inflection of 'function' and 'use', it is also worthwhile to revisit his larger conception of architectural theory as a whole. In the conference address mentioned at the beginning of this paper, Banham makes a series of broad observations about the state of the art, including the argument that there is no discipline of architectural theory, or not any longer, and certainly not in the architecture schools, where the term becomes simply a term for anything that won't fit anywhere else.

The category "theory of architecture" having become vacuous, empty of formal content and devices, has been used as a sort of general purpose carrier-bag or hold-all, into which you stuff sociology, computer programming, and anything else which cannot be taught at the drawing board but which you feel architects ought to know (Banham 1965: 93). 
But more pointedly, Banham argues that it is precisely in response to a functional brief, provided by a client, that the architect's actual creative work occurs. In everyday practice architects do not, or not commonly, invent and motivate projects on their own, either funded by themselves or 'sold' entrepreneurially to an investor. Banham notes that architects, like lawyers or engineers, thus make a professional life of standing ready to be 'propositioned' by a client, they 'depend upon someone coming forward with the proposition in one hand and the money bag in the other' (Banham 1965: 94). His point here is that the interesting and valuable and critiquable aspects of architectural practice are reactive to a specific programmatic task provided from outside, and to ignore this in favour of the elements of architectural practice which are either generic (not specific to the task at hand) or autonomous (somehow particular to architectural practice independent of its fulfilment of a task) is to miss the point at both ends of the scale. Banham goes on to make a strong case for the primacy of functional concerns in architectural criticism.

It is impossible to discuss the building without discussing what it is for. Above all, to treat utility as an affliction, as something that should be set on one side in discussing a building, is to leave out the reasons why the building was created in the first place and the performance that society expects of it. If you leave out the fact of utility, you leave out the "why" of architecture as a human activity; yet a great deal of architectural writing appears to (and has to) support this dichotomy of method (Banham 1965: 92).

From this he continues on to argue that the critic of a given building needs to have a thorough and expert knowledge of the brief in order to say anything usefully specific about it. Perhaps more controversially, he also argues that it is necessary to have direct knowledge of the architect's intentions, and that criticism should concern itself with the 'biography' of the architect in the professional situation, and thus of the entire 'life' of the project from the point at which the task is accepted.

\section{The limits of architecture}

In the last essay he wrote before he died, Banham sought those things that distinguish architecture from other types of design or manufacturing process. Describing the arcane aesthetic conventions of architecture as a 'black box', he argued, radically, for it to be understood within much more highly circumscribed boundaries. This was explicitly an argument against the colonising tendencies of architectural discourse, the 'vulgar cultural imperialism that leads the writers of general histories of architecture to co-opt absolutely everything built upon the earth's crust into their subject matter' (Banham 1996: 297), just as it was an argument for architecture to be seen as a process rather than a product. More than this, his argument hinges on a specific historical and geographically located lineage.

Recognising the very straightened boundaries of architecture as an academically teachable subject, we might deceive and confuse ourselves less if we stopped trying to cram the whole globe into its intellectual portfolio. We could recognise that the history of architecture is no more, but emphatically no less, than what we used to believe it was: the progression of those styles and monuments of the European mainstream, from Stonehenge to the Staatsgallerie, that define the modest building art that is ours alone (Banham 1996: 297).

In this conception, it is precisely drawings, in the strictly middle-Italian sense of disegno, that distinguish architecture as a practice and as an art. This would immediately exclude those design practices that do not employ drawings, such as those based on patterns, or on direct, applied adjustment at the time of manufacture. As an example Banham describes the case of ice cream vans, which he describes as 'the biggest invisible objects in residential Britain', the design and manufacture of which were, at the time and place of his writing, dominated by a single company. He describes the way that this firm operates entirely without drawings or 'design' as such, but nevertheless produces remarkably sophisticated 'styled' objects, drawing inflections from popular culture such that there is an identifiable 'Rocket-Baroque phase', influenced by the aesthetic of the space race and of Batman. The point here is that even constructions like this might, in the kind of omnivorous discourse prevalent at the time and continuing even more extremely today, be taken as architecture, but that this would be a disservice both to architecture and to ice-cream vans. In Banham's schema, his ice-cream van manufacturer has a working process closer to artisan masons working on a gothic cathedral, than to the drawn at the board processes of architecture. And even though both artefacts must be understood in their respective highly encoded cultural and social contexts, the evaluation of architecture must always be relative to that past architect, their intentions, and the drawings that result from them. 


\section{Conclusion}

To return to Banham's quip with which I began this paper, that 'history is my academic discipline, criticism is what I do for money', it is precisely through criticism of the everyday ephemera of popular culture than Banham reads history in the present moment. Thus the idea of the 'throw-away line' also becomes curiously appropriate - in Banham's terms it is precisely those things we consume and then toss aside that define our contemporary culture, and in his attempt to make journalistic writing as current and disposable as the things that he wrote about, Banham also approached a kind of durability, even timelessness. This method continues to hold currency today - Walter Vanstiphout, has extended the list of 'Banham's urban gizmos' to include such present day items as 'the Powerbook, the condom dispenser, the cellphone, the methadone van, the mobile sound system, and the freight container. In these and other gizmos one sees contemporary life' (Vanstiphout 1998:4). This archaeology of the present, particularly inflected through the technology that permeates every aspect of life, continues to reveal Banham's work as an enduring model for critical practice.

\section{References}

Banham, Reyner. "A Black Box: The Secret Profession of Architecture." A Critic Writes: Essays by Reyner Banham, Ed. Mary Banham, Paul Barker, Sutherland Lyall and Cedric Price. Berkeley: University of California Press, 1996. 292-299.

Banham, Reyner. "Convenient Benches and Handy Hooks: Functional Considerations in the Criticism of the Art of Architecture." The History, Theory and Criticism of Architecture: Papers from the 1964 AIA-ACSA Teacher Seminar. Ed. Marcus Whiffen. Cambridge, Mass.: MIT Press, 1965. 91-105.

Banham, Reyner. "Foreword." Design By Choice. Ed. Penny Sparke, London: Academy Editions. 1981. 7.

Banham, Reyner. "Shades of Summer." New Society (June 29, 1967): 959.

Banham, Reyner. "Vehicles of Desire." A Critic Writes: Essays by Reyner Banham, Ed. Mary Banham, Paul Barker, Sutherland Lyall and Cedric Price. Berkeley: University of California Press, 1996. 3-6.

Golan, Romy. "Book Review - Reyner Banham: Historian of the Immediate Future." The Art Bulletin. (June 2003): 401-405.

Hall, Peter. "Foreword." A Critic Writes: Essays by Reyner Banham. Ed. Mary Banham, Paul Barker, Sutherland Lyall and Cedric Price. Berkeley: University of California Press, 1996: xixv.

Katz, Barry. "Book Review: Reyner Banham: Historian of the Immediate Future." Technology and Culture 43 (October 2002): 798-800.

McAuliffe, Mary. "Book Review - A Critic Writes: Essays by Reyner Banham." Journal of the Society of Architectural Historians 59 (June 2000): 268-270.

Stephens, Suzanne. "Assessing the State of Architectural Criticism in Today's Press." Architectural Record 186 (1998): 64-69.

Vanstiphout, Walter. "Book Review - A Critic Writes: Essays by Reyner Banham." Harvard Design Magazine 5 (1998): 1-4.

Whiteley, Nigel. "Banham and 'Otherness': Reyner Banham (1922-1988) and his quest for an architecture autre." Architectural History 33 (1990): 188-221.

Whiteley, Nigel. "Olympus and the Marketplace: Reyner Banham and Design Criticism." Design Issues 13 (Summer 1997): 24-35.

Whiteley, Nigel, Reyner Banham: Historian of the Immediate Future. Cambridge, Mass.: MIT Press, 2002. 